\title{
The Resurgence of Leprosy in India: Findings from a Survey Assessing Medical Professionals’ Knowledge and Preparedness
}

\author{
Pugazhenthan Thangaraju, Sajitha Venkatesan, Tamil Selvan T', Elavarasan Sivshanmugam, M. K. Showkath Ali \\ Department of Clinical Division, Central Leprosy Teaching and Research Institute, Kanchipuram, Tamil Nadu, 'S School of Information Technology, SRM University, \\ Gangtok, Sikkim, India
}

\section{Abstract}

Background: Sufficient knowledge regarding presentation, clinical features, and further workup of leprosy, a stigmatized disease, is essential for physicians and other health professionals to effectively control the disease. This study aimed to investigate the current knowledge of leprosy among health professionals in India. Materials and Methods: An online survey was administered to 200 health-care professionals. Results: One hundred and thirteen health professionals representing various sectors completed the survey. Only $24 \%$ of participants correctly answered items regarding the treatment of mild reactions of Type 1 reversal reaction and Type 2 erythema nodosum leprosum. In addition, only $38 \%$ of participants correctly answered an image-based item depicting a blister calendar pack used for treatment. Conclusion: The survey results indicate that medical professionals need more educational training to combat this once declared "eliminated" disease.

Keywords: Health professionals, knowledge, leprosy, survey, web based

\section{INTRODUCTION}

Leprosy is a chronic granulomatous infectious disease caused by low virulent Mycobacterium leprae and Mycobacterium lepromatosis through droplet infection. The primary area of affection is skin and nerves ${ }^{[1]}$ Due to variability in the host immune system, the clinical spectrum of the illness varies from a very mild and limited cutaneous disease to a severe and extensive nerve and systemic organ involvement. The severe form of the disease ends with various mutilating deformities and disabilities with a high disability index. ${ }^{[2]}$ Early recognition and prompt therapeutic intervention in drug regimens recommended by the World Health Organization (WHO) are prudent to halt the disease and from developing disabilities. ${ }^{[3]}$ Currently, leprosy is a fairly common infectious disease with a worldwide distribution. ${ }^{[4]}$ Leprosy is a disease surrounded with social stigma due to the resulting disabilities and deformities in severe cases. The disease was declared eliminated at the national level in December 2005, but to our surprise, there remain new cases diagnosed from various districts and blocks of India that contribute to a prevalence rate of approximately one in every 10,000 members of the population. As per the epidemiological record of India, approximately 127,326 new leprosy cases were detected and 86,028 cases were on record as

\begin{tabular}{|c|c|}
\hline \multicolumn{2}{|c|}{ Access this article online } \\
\hline 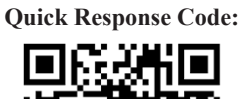 & $\begin{array}{l}\text { Website: } \\
\text { www.ehpjournal.com }\end{array}$ \\
\hline 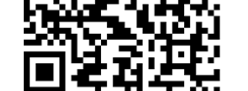 & $\begin{array}{l}\text { DOI: } \\
\text { 10.4103/EHP.EHP_3_18 }\end{array}$ \\
\hline
\end{tabular}

of March 31, 2016. Further, the percentage of severe Grade II disability among new cases detected has been increased to $4.61 \%$ between 2014 and 2015, which indicates that the cases are being detected late in the community, and there may be several cases which are lying undetected or hidden. ${ }^{[5]}$

In the postelimination era, the most health-care professionals have demonstrated little concern for this disease. Similarly, at our hospital in southern India, we observed that the most health-care professionals had a limited knowledge about leprosy. This prompted us to conduct a formal knowledge assessment about leprosy, as sufficient knowledge regarding presentation, clinical features, and further workup of leprosy is essential for physicians and other health professionals to effectively control the disease. ${ }^{[6]}$ Thus, the purpose of this study was to assess the level of knowledge of health-care professionals in southern India about leprosy and the drugs used for treating the disease.

Address for correspondence: Dr. Pugazhenthan Thangaraju, Central Leprosy Teaching and Research Institute, Chengalpattu, Kanchipuram - 603 001, Tamil Nadu, India. E-mail: drpugal23@gmail.com

This is an open access journal, and articles are distributed under the terms of the Creative Commons Attribution-NonCommercial-ShareAlike 4.0 License, which allows others to remix, tweak, and build upon the work non-commercially, as long as appropriate credit is given and the new creations are licensed under the identical terms.

For reprints contact: reprints@medknow.com

How to cite this article: Thangaraju P, Venkatesan S, Selvan TT, Sivshanmugam E, Showkath Ali MK. The resurgence of leprosy in India: Findings from a survey assessing medical professionals' knowledge and preparedness. Educ Health Prof 2018;1:24-7. 


\section{Materials and Methods}

An online survey was developed to evaluate the knowledge level and practices of medical professionals regarding leprosy and its pharmacotherapy. The instrument was developed by two independent physicians working in the field of leprosy. Feasibility of the instrument was evaluated in a pilot survey involving a convenience sample. On completion of the pilot survey, the final instrument was distributed through E-mail to 200 medical professionals during the months of June and July 2017. Participants consisted of members of a closed group, mainly doctors of native Tamil Nadu and nearby states. Each participant received a minimum of two reminders to complete the survey. Human participants' approval was not required for this assessment.

The survey consisted of three sections and contained 23 items. The first section consisted of four questions inquiring about the demographic characteristics (e.g., age, sex, qualification, and specialty) of the participating health-care professionals. The second section consisted of 17 multiple choice items (including one image-based item) about leprosy, treatment, and lepra reaction [Table 1]. The third section consisted of two yes/no items regarding personal experience seeing/treating leprosy. Data were analyzed using descriptive statistics.

\section{RESULTS}

A total of 113 participants completed the survey, resulting in a 56.5\% response rate. Participants consisted of 69 males and 39 females (five participants did not indicate a sex). Most participants ( $n=89,78.76 \%)$ were between the ages of 20 and 30 years. The next largest age group $(n=17,15 \%)$ consisted of 31-40 years old. Most participants $(n=53,46.90 \%)$ held MBBS/BDS degrees, followed by postgraduate MD/MS/MDS degrees $(n=27,23.89 \%)$ with the remainder ( $n=26,23 \%)$ consisting of students in medical and dentistry programs.

The second part of the survey consisted of items regarding leprosy, treatment, lepra reactions, and management. Results indicate $91.15 \%$ of participants could discern leprosy and its classification. About $90.26 \%$ correctly identified the drugs used in paucibacillary (PB) and $76.10 \%$ correctly identified the duration of treatment for PB. In addition, $86.72 \%$ of participants correctly identified the drugs used in multibacillary (MB) and $54.87 \%$ correctly identified the duration of treatment for MB. Only $38.5 \%$ of participants correctly answered an image-based item depicting a blister calendar pack used for the treatment.

About $90.26 \%$ of participants correctly identified lepra reactions but failed to answer most other items correctly. More specifically, $42.48 \%$ correctly responded to lepra reaction occurrences, and only $23.89 \%$ responded correctly to items pertaining to the correct treatment of mild reactions in both types. About $64.60 \%$ of participants responded correctly to the items pertaining to the proper treatment of moderate-to-severe Type 1 reactions. Approximately $70 \%$ of participants responded correctly to proper indication of steroids in the treatment of

\begin{tabular}{|c|c|}
\hline Item & Correct (\%) \\
\hline \multicolumn{2}{|l|}{ 1. What is leprosy? } \\
\hline Chronic granulomatous condition & $103(91.15)$ \\
\hline \multicolumn{2}{|l|}{ Caused by Mycobacterium leprae } \\
\hline \multicolumn{2}{|l|}{$100 \%$ curable when diagnosed earlier } \\
\hline \multicolumn{2}{|l|}{ All the above } \\
\hline \multicolumn{2}{|l|}{ 2. Classification of leprosy as per the WHO } \\
\hline PB (paucibacillary) & $103(91.15)$ \\
\hline \multicolumn{2}{|l|}{ MB (multibacillary) } \\
\hline \multicolumn{2}{|l|}{ Both } \\
\hline \multicolumn{2}{|l|}{ None } \\
\hline \multicolumn{2}{|l|}{ 3. Duration of treatment for $\mathrm{PB}$} \\
\hline 6 months completed within 9 months & $86(76.10)$ \\
\hline \multicolumn{2}{|l|}{9 months completed within 12 months } \\
\hline \multicolumn{2}{|l|}{12 months completed within 18 months } \\
\hline \multicolumn{2}{|l|}{ None of the above } \\
\hline \multicolumn{2}{|l|}{ 4. Duration of treatment for $\mathrm{MB}$} \\
\hline 6 months completed within 9 months & $62(54.87)$ \\
\hline \multicolumn{2}{|l|}{9 months completed within 12 months } \\
\hline \multicolumn{2}{|l|}{12 months completed within 18 months } \\
\hline \multicolumn{2}{|l|}{ None of the above } \\
\hline \multicolumn{2}{|l|}{ 5. Drugs used in PB } \\
\hline Rifampicin & $102(90.26)$ \\
\hline \multicolumn{2}{|l|}{ Dapsone } \\
\hline \multicolumn{2}{|l|}{ Clofazimine } \\
\hline \multicolumn{2}{|l|}{$\mathrm{A}$ and $\mathrm{B}$} \\
\hline \multicolumn{2}{|l|}{$\begin{array}{l}\text { 6. Which blister calendar pack is used to treat } \\
\text { leprosy? (image) }\end{array}$} \\
\hline $\mathrm{PB}(\mathrm{A})$ and $\mathrm{MB}(\mathrm{A})$ & $43(38.05)$ \\
\hline \multicolumn{2}{|l|}{$\mathrm{PB}(\mathrm{C})$ and $\mathrm{MB}(\mathrm{C})$} \\
\hline $\mathrm{PB}(\mathrm{A})$ and $\mathrm{MB}(\mathrm{C})$ & \\
\hline None of the above & \\
\hline 7. Drugs used in $\mathrm{MB}$ & \\
\hline Rifampicin & $98(86.72)$ \\
\hline Clofazimine & \\
\hline Dapsone & \\
\hline All the above & \\
\hline 8. Lepra reactions occur & \\
\hline The first time as the bacilli enters into body & $48(42.48)$ \\
\hline During treatment & \\
\hline After treatment & \\
\hline All the above & \\
\hline 9. Types of reactions & \\
\hline Type 1 or reversal reaction & $102(90.26)$ \\
\hline Type 2 or erythema nodosum leprosum & \\
\hline Both & \\
\hline None of the above & \\
\hline 10. Treatment of mild reactions both types & \\
\hline Adequate dose of analgesics & $27(23.89)$ \\
\hline Steroids & \\
\hline Both A and B & \\
\hline $\begin{array}{l}11 . \text { Only a treatment of moderate-to-severe type } 1 \\
\text { reaction }\end{array}$ & \\
\hline Adequate dose of analgesics & $73(64.60)$ \\
\hline
\end{tabular}

Contd... 


\begin{tabular}{|c|c|}
\hline Item & Correct (\%) \\
\hline \multicolumn{2}{|l|}{ Steroids in case of neuritis } \\
\hline \multicolumn{2}{|l|}{ Both A and B } \\
\hline \multicolumn{2}{|l|}{ Thalidomide } \\
\hline \multicolumn{2}{|l|}{ 12. Steroids indications } \\
\hline Skin flare reactions without neuritis & $78(69.02)$ \\
\hline \multicolumn{2}{|l|}{ Skin flare reactions with neuritis } \\
\hline \multicolumn{2}{|l|}{ Neuritis with functional involvement } \\
\hline \multicolumn{2}{|l|}{ Both $\mathrm{B}$ and $\mathrm{C}$} \\
\hline \multicolumn{2}{|l|}{ 13. Treatment of moderate-to-severe ENL } \\
\hline High dose of analgesics and NSAIDs & $78(69.02)$ \\
\hline \multicolumn{2}{|l|}{ Steroids - neuritis } \\
\hline \multicolumn{2}{|l|}{ Clofazimine } \\
\hline \multicolumn{2}{|l|}{ Thalidomide } \\
\hline \multicolumn{2}{|l|}{$\begin{array}{l}\text { 14. All the above according to situations dosage of } \\
\text { steroids as per the WHO }\end{array}$} \\
\hline Max. up to $1 \mathrm{mg} / \mathrm{kg} /$ body weight & $60(53.09)$ \\
\hline \multicolumn{2}{|l|}{$2 \mathrm{mg} / \mathrm{kg} /$ body weight } \\
\hline \multicolumn{2}{|l|}{$20 \mathrm{~g} /$ day } \\
\hline \multicolumn{2}{|l|}{$10 \mathrm{~g} /$ day } \\
\hline \multicolumn{2}{|l|}{ 15. WHO/NLEP tapering of steroids } \\
\hline $\begin{array}{l}40 \mathrm{mg} / \text { day tapering every forth nightly by reduction } \\
\text { of } 10 \mathrm{mg} \text { till } 20 \mathrm{mg} \text {, then by } 5 \mathrm{mg} \text { till } 5 \mathrm{mg}\end{array}$ & $40(35.40)$ \\
\hline \multicolumn{2}{|l|}{$\begin{array}{l}\text { Increase of duration in every dose to maximum of } \\
\text { still } 2 \text { weeks still symptoms subsides }\end{array}$} \\
\hline \multicolumn{2}{|l|}{ Max. 12 weeks of treatment for type 1 reactions } \\
\hline \multicolumn{2}{|l|}{ All the above } \\
\hline \multicolumn{2}{|l|}{ 16. Dosage and duration of clofazimine } \\
\hline $\begin{array}{l}100 \mathrm{mg} \text { tds tapering } 100 \mathrm{mg} \text { every month for } \\
\text { maximum of } 12 \text { months }\end{array}$ & $48(42.48)$ \\
\hline \multicolumn{2}{|l|}{$\begin{array}{l}100 \mathrm{mg} \text { tds tapering } 100 \mathrm{mg} \text { every month for } \\
\text { maximum of } 24 \text { months }\end{array}$} \\
\hline \multicolumn{2}{|l|}{$\begin{array}{l}100 \mathrm{mg} \text { tds tapering } 100 \mathrm{mg} \text { every month for } \\
\text { maximum of } 48 \text { months }\end{array}$} \\
\hline \multicolumn{2}{|l|}{ None of the above } \\
\hline \multicolumn{2}{|l|}{ 17. Indication for thalidomide } \\
\hline $\begin{array}{l}\text { Tachyphylaxis of steroids/contraindication for } \\
\text { steroids }\end{array}$ & $70(61.95)$ \\
\hline \multicolumn{2}{|l|}{$\begin{array}{l}\text { No clinical improvement with steroids and } \\
\text { clofazimine }\end{array}$} \\
\hline \multicolumn{2}{|l|}{ Both A and B } \\
\hline None of the above & \\
\hline
\end{tabular}

lepra reactions and the treatment of moderate-to-severe erythema nodosum leprosum (ENL). Slightly more than half of these participants (53.09\%) correctly identified the proper dosage of steroids per the WHO guidelines, and $35.40 \%$ correctly identified the proper tapering of steroids per the WHO guidelines. Approximately $40 \%$ of participants correctly identified the dosage and duration of clofazimine for the treatment, and about $62 \%$ correctly identified the indications of using thalidomide in lepra reaction.

In the third section of the survey, $87 \%$ of health-care professionals surveyed indicated that they have seen at least one case of leprosy. Approximately $42 \%$ have diagnosed leprosy in their practice. A complete breakdown of results is presented in Table 1.

\section{Discussion}

This study is the first of its kind to assess leprosy knowledge among health-care professionals in India. In the postelimination era of leprosy, India has encountered an increasing number of outpatient and surgical Grade 2 disability cases. Thus, it is vital to identify a relative estimate of baseline knowledge of leprosy among health-care professionals for identifying and appropriately treating this disease.

A few studies have been conducted involving medical students ${ }^{[7]}$ and public health-care professionals ${ }^{[8]}$ using self-reported questionnaires. Our study is the first web-based survey among health-care professionals where lepra reaction and management were also investigated.

Alarmingly, approximately half of the participants correctly identified how to properly treat mild, moderate, and severe reactions, and approximately half responded for steroids indications in lepra reaction as whom to be started, when to be started, at what dose should be started, and how tapering of the steroid should be done in accordance with the WHO reaction management guideline. Only $42 \%$ of participants correctly identified the use of clofazimine for the treatment. This indicates less than half of participants were aware of clofazimine as a drug used as an anti-inflammatory in the management of Type 2 lepra reaction. Although thalidomide is rarely used to treat lepra reaction, more than $60 \%$ of respondents correctly identified this treatment option. The likely reason is that, in most available medical textbooks, the adverse effects of thalidomide are commonly highlighted as the causation for teratogenicity in addition to its approved indication in ENL and multiple myelomas. ${ }^{[9]}$

The lepra reactions are managed based on the classification of reaction, severity categorization, and the use of appropriate drugs based on a severity scale. For managing mild reactions, only nonsteroidal anti-inflammatory drugs (NSAIDs) were used in both Type 1 and Type 2 reactions. In severe cases of both types, especially in Type 1 reaction with neuritis and fever, the corticosteroids were the mainstay of drugs in treatment protocol. Only $50 \%$ of the health-care professionals were aware of steroid treatments in the reaction. The main reasons for recurrence of reaction in some patients were due to irrational planning of dose and preparation of steroids. This phenomenon also is depicted in our survey, as only $50 \%$ of health professionals were knowledgeable about steroid usage in the treatment of lepra reactions. A troubling finding is that only $35 \%$ of participants know the proper protocol for tapering steroids.

As noted previously, the severity categorization is the primary consideration when planning a treatment regimen. Therefore, the question on the treatment of mild reaction of both types 
was a targeted question that helped us to identify the current knowledge of health-care professionals and how they tend to manage the mild reaction at their setting of practice. To our surprise, only $23.89 \%$ of participants correctly identified the drugs that should be used in that situation. We found that with respect to the management of a mild reaction many doctors at tertiary care centers have prescribed the WHO steroid protocol for a mild reaction, where the actual treatment for a mild reaction should be only NSAIDs.

Information obtained from this knowledge assessment helped us to plan for teaching and developing training modules in leprosy, lepra reaction, and its management for different groups of medical professionals. We currently provide training in our institute for health professionals such as nonmedical supervisors, medical interns, postgraduate medical students (e.g., community medicine, dermatology), medical officers, district leprosy officers, state leprosy officers, and consultants. However, training also is now underway for health-care professionals in tertiary settings such as medical colleges, primary health centers, and other centers that specialize in leprosy. It is hoped that with additional education and proper training, this once declared that "eliminated" disease will truly be eliminated once and for all.

\section{ConcLusion}

This knowledge assessment examined the current knowledge of health professionals with respect to various aspects of leprosy. We found deficiency in important areas of leprosy reaction and its management. Training protocol has been created to educate health-care professionals about the proper diagnosis and treatment of leprosy. It is our hope to eliminate leprosy in India once and for all.

\section{Financial support and sponsorship}

Nil.

\section{Conflicts of interest}

There are no conflicts of interest.

\section{REFERENCES}

1. Bryceson A, Pfaltzgraff RE. Leprosy. $3^{\text {rd }}$ ed. Edinburgh: Churchill Livingstone; 1990.

2. Soomro FR, Pathan GM, Abbasi P, Bhatti NS, Yoshihisahashiguchi. Deformity and disability index in patients of leprosy in Larkana region. J Pak Assoc Dermatol 2008;18:29-32.

3. Global Distribution of New Leprosy Cases; 2015. Available from: http:// www.who.int/lep/epidemiology/en/. [Last accessed on 2018 May 24].

4. van Brakel WH. Measuring leprosy stigma - A preliminary review of the leprosy literature. Int J Lepr Other Mycobact Dis 2003;71:190-7.

5. Thangaraju P, Venkatesan S, Showkath Ali MK. Final leprosy push: Out of society. Indian J Community Med 2018;43:58-9.

6. Barkakaty BN. How can the private practitioners support leprosy elimination in India. J Indian Med Assoc 2006;104:673-4.

7. Leena R, Priya KS. A study of knowledge and attitude about leprosy among medical students. Indian J Lepr 2017;89:91-7.

8. Wijeratne MP, Ostbye T. Knowledge, attitudes and practices relating to leprosy among public health care providers in Colombo, Sri Lanka. Lepr Rev 2017;88:75-84.

9. Castilla EE, Ashton-Prolla P, Barreda-Mejia E, Brunoni D, Cavalcanti DP, Correa-Neto J, et al. Thalidomide, a current teratogen in South America. Teratology 1996;54:273-7. 